\title{
Political Advertising on the Wikipedia Marketplace of Information
}

Social Science Computer Review 2018, Vol. 36(2) 157-175 (C) The Author(s) 2017 Reprints and permission: sagepub.com/journalsPermissions.nav DOI: $10.1177 / 0894439317703579$ journals.sagepub.com/home/ssc

(SAGE

\author{
Sascha Göbel' and Simon Munzert ${ }^{2}$
}

\begin{abstract}
We point to a popular yet underresearched platform of political information, the online encyclopedia Wikipedia. Considering the supply side of the marketplace, we argue that personal biographies on the platform are an attractive medium for politicians to enhance their appearance. We trace changes to biographies coming from the parliament using data that cover the entire edit histories for biographies on all German members of parliament for the three last legislative periods. Our findings show editing of personal biographies to be a persistent phenomenon. Moreover, type, timing, and driving factors of editing behavior highlight the importance politicians' attribute to Wikipedia for pursuing reelection. Our results speak to the domains of political professionalization, voting behavior, and the general measurement of communicative patterns.
\end{abstract}

\section{Keywords}

new media and political communication, elections and campaigns, measurement, data collection, Wikipedia

Political communication styles and techniques have changed fundamentally since the Internet became an integral part of political interaction in the early 2000s (Dahlgren, 2005). Politicians have discovered personal home pages and weblogs as well as Twitter, Facebook, and YouTube accounts as indispensable tools for political marketing and electoral campaigning. Similarly, most members of parliament (MPs) in advanced democracies have an entry on the largest and most popular online encyclopedia, Wikipedia. Providing new means for politicians to connect with voters and shape public opinion, these digital spaces present fruitful avenues to investigate the behavior of political elites. Yet, while websites and social networking services such as Facebook or Twitter have received considerable academic attention in this regard (e.g., Druckman, Kifer, \& Parkin, 2007; Gibson \& McAllister, 2011; Lassen \& Brown, 2011), Wikipedia has gone largely unnoticed. Indeed, research on Wikipedia has been predominantly technical, focusing, for instance, on the size, reliability, and

\footnotetext{
' University of Konstanz, Konstanz, Germany

${ }^{2}$ Department of Social Sciences, Humboldt University of Berlin, Berlin
}

\section{Corresponding Author:}

Simon Munzert, Humboldt University of Berlin, Department of Social Sciences, Universitätsstr. 3b, 10099 Berlin, Germany. Email: simon.munzert@hu-berlin.de 
creation processes of encyclopedic content rather than on social science issues (Mesgari, Okoli, Mehdi, Nielsen, \& Lanamäki, 2015; Schroeder \& Taylor, 2015).

Our article addresses this gap by exploring revision patterns on politicians' Wikipedia biographies. We argue that Wikipedia is an attractive platform for political candidates to advertise themselves to their constituencies in comparison with other online channels of political communication, as it is a widely used source of political information and, perhaps as important, one that is often deemed neutral. Being a free and collective endeavor of knowledge production where everyone at any point in time can edit content, Wikipedia brings together a multitude of values, beliefs, and opinions when dealing with contentious issues such as politics. This makes it a place for active political communication. Fortunately, Wikipedia stores every detail of these interactions in publicly accessible edit histories.

To the best of our knowledge, this study is the first to investigate these edit histories in order to uncover parliamentary interferences in the evolution of politicians' Wikipedia entries. It relies on data featuring 108,775 edits that pertain to the Wikipedia profiles of all 1,100 members of the three last legislative sessions of the German parliament (Bundestag). Taking a longitudinal approach, we investigate if and how edit histories are linked to off-line political events, such as election campaigns. Furthermore, we test whether strategic incentives rooted in the electoral system as well as other political and sociodemographic characteristics predict editing behavior. In doing so, we primarily focus on edits stemming from the parliament, as traced by the Internet Protocol (IP) addresses of the respective authors.

Our analyses reveal editing of personal Wikipedia biographies coming from the parliament's IP range to be a persistent phenomenon identified for more than half of the MPs in our sample. In addition, distinct editing types clearly link to various strategic motifs. While we find that edits originating in parliament occur all the time rather than peaking during election periods, the political and sociodemographic factors we test for with view to the probability and intensity of editing highlight (re)election motifs. In sum, our findings support the notion that politicians are well aware of and strategically exploit Wikipedia's unique features.

The work reported here contributes to the existing literature in various ways. For one thing, it adds to research regarding the ongoing professionalization of political campaigning and the part the Internet takes in that context. In particular, it complements our knowledge about legislators' political behavior on the Internet, about which tools MPs use, and about how and why they use them. Second, we introduce edit histories on Wikipedia as a new data source for the study of elite behavioral patterns that allow for a more beneficial and fine-grained measure of activity compared to traditionally used sources such as surveys. Finally, by placing the analytical focus not on the communication platform but on the behavioral patterns revolving around politicians on that platform, we extend the so far mainly technical research on Wikipedia to tackle central questions in political and social science research.

In the next section, we start with a brief review of Wikipedia as a marketplace for political information and of relevant research on this platform. Next, we present the theoretical foundations of our work, describing possibilities to edit content on Wikipedia and discussing incentives for politicians to do so. We then describe our case selection, data collection procedure, and analytical strategy. The penultimate section presents our empirical findings. The article concludes with a discussion of the results and routes for future research.

\section{Wikipedia as a Marketplace for Political Information}

Over the years, Wikipedia has grown to be a major and trusted source of information that has outpaced traditional encyclopedias in terms of reach, coverage, and comprehensiveness (Giles, 2005). Being the fifth most-visited website worldwide ${ }^{1}$ emphasizes its importance for modern 
society. People consult Wikipedia to satisfy their curiosity or information deficit in a reaction to sudden events like celebrity deaths or political conflict and also to inform themselves about niche issues not regularly covered by mainstream media. When it comes to political information, the online encyclopedia covers a variety of topics, including political systems, highly specific policy issues, election results, and biographies of politicians.

However, Wikipedia is more than a passively used source of information: One of its most distinctive features is its free accessibility and editability. It is important to note that editing activity on Wikipedia is not limited to a small group of highly devoted but ideologically neutral Internet geeks. Users openly proclaim their political affiliation on Wikipedia and discuss intensively about article content (Neff et al., 2013). Veritable "edit wars" erupt on particularly controversial issues such as climate change, off-line political conflict phenomena, or certain biographic entries (Sumi, Yasseri, Rung, \& Kertész, 2012). Moreover, negative facts on entries belonging to active politicians are more likely to be removed than positive ones and more quickly than for dormant or deceased politicians (Kalla \& Aronow, 2015). As we demonstrate later, it is possible to infer how elite political actors use Wikipedia to tweak their online biographies. In that sense, Wikipedia is far from being a passive medium. It provides a vibrant marketplace for political information where a variety of users continuously negotiate existing content.

\section{Editing on Wikipedia: Mechanisms and Incentives}

In this study, we take an elite perspective on editing of Wikipedia articles. Our core interest is to identify when and how biographical entries of MPs are subject to editing and what role politicians themselves play in this marketplace for information. To answer these questions, we elaborate on the mechanisms of editing content on Wikipedia as well as on MPs' incentives to do so.

The management of Wikipedia content has always been a contentious matter. This especially applies to biographic representations of living persons (Das, Lavoie, \& Magdon-Ismail, 2011) and is rooted in Wikipedia's structural features. In particular, the encyclopedia allows its users not just to add content (insertions) but also to remove it (deletions). ${ }^{2}$

To become active, however, individuals must have incentives to invest their scarce time resources into editing efforts. The strongest incentives for individuals in this regard are simply their interest in certain subjects or their expertise in specific areas (Lieberman \& Lin, 2009). As concerns political content, research has proven those more prone to off-line political participation to also exploit Internet opportunities and resources the most (Brundidge \& Rice, 2009). This suggests that those who edit political content and MP profiles are likely to hold at least basic political values, beliefs, and opinions. It can thus be reasonably assumed that editors of MPs' Wikipedia profiles are, even if unknowingly so, prone to push their point of view in line with their own political or party preferences (Kalla \& Aronow, 2015; Neff et al., 2013). In an interview with leading Wikipedia practitioners, Riehle (2006, p. 6) shows that the practice to enforce one's own point of view constitutes the most frequent type of conflict on Wikipedia. Consequently, one cannot expect Wikipedia's neutral point of view policy ${ }^{3}$ to prohibit politically biased editing.

Now, what counts for common Wikipedia users must not be different for MPs, except that MPs have even higher motivation to become active as editors if their own entry affects personal prospects of winning an election. The Internet's general importance for individual campaigning efforts is evident in the vote-seeking behavior MPs show on the Internet (Zittel, 2015) and the benefits they gain from using online opportunities (Gibson \& McAllister, 2011; Utz, 2009).

We argue that among these opportunities, Wikipedia constitutes a highly efficient and as such attractive site for political campaigning. In particular, biographical entries on Wikipedia allow politicians to connect with and sway voters while maintaining full control over the information flow in ways not provided by other platforms. Aside from increasing their online visibility, MP 
profiles on Wikipedia uniquely permit politicians to not only target but also reach their primary audience. As shown by Druckman, Kifer, and Parkin (2009), politicians' online appearances are above all meant to catch undecided voters who at the same time are found least likely to actively follow politicians campaign websites or social media channels. This mismatch is less apparent on Wikipedia. The platform's link structure and status as widely employed and primary web information source make it highly probable to be visited by undecided voters who have a higher information deficit than engaged voters or party supporters.

Furthermore, MPs can utilize their biographies to pursue basic vote-seeking activities (see Mayhew, 1974) at comparatively low costs. Wikipedia biographies can promote the MP as a person (advertising), expose her personal efforts for the constituency (credit claiming), and document her political stance (position taking), probably even contrasting the own party's positions. Geared toward interactivity, social media channels are too fast moving and lack an equally informationrich and structured environment demanding much more effort to fulfill these same tasks. Similarly, the construction and maintenance of websites comes with considerable technical and financial resource requirements. Wikipedia entries, on the other hand, are usually created and cared for by others, allowing MPs to concentrate their scarce resources on specific, easily, and quickly managed editing activities.

Finally, Wikipedia offers politicians a remarkable level of control over the information flow. First, MPs can utilize their profile to distribute personal information aloof from channels that are controlled by the party or the media, allowing them to bypass effects of editorial slant on voters (Druckman \& Parkin, 2005). Second, MPs can decide to selectively add, remove, or reframe (Chong \& Druckman, 2007) content in an attempt to shape their appearance to their advantage. Third, and arguably most importantly, MPs can do all this without the reader even noticing. After all, while the brains and motivation behind campaign websites, social media, or ads are known from the start and may stain the sources' credibility and trustworthiness, this is not the case for an encyclopedic entry.

This last point marks one of the key differences between Wikipedia editing and other forms of online campaigning, namely, that it can be used for that purpose in a very subtle manner. People do not visit Wikipedia entries on their local MP to be deliberately primed with the MP's personal opinion. Wikipedia is used as a source of information, not opinion, and as such, it is often deemed neutral. According to a Wikipedia Readership Survey among 4,000 participants conducted during 2011 in 16 countries, readers rated the page as particularly trustworthy (average of 7.5 on a 10-point scale) and neutral in terms of "information providing a balanced point of view" (average of 7.6 on a 10-point scale). ${ }^{4}$ Moreover, more than half of the respondents explicitly stated they chose Wikipedia over other Internet sources while searching the Internet because of its trustworthiness. This has important implications for the impact of information provided and edited on Wikipedia. Those highly trusting of an information source are also most susceptible to be influenced by the information they gain from it (Miller \& Krosnick, 2000). To be sure, the above does not imply that Wikipedia is necessarily superior to other platforms as a channel of political communication. Indeed, Wikipedia lacks many possibilities offered by social media platforms. However, the unique combination of possibilities offered by Wikipedia and the fact that it speaks to a completely different audience make it possible to study modes of online political communication different from those offered by social media channels.

In sum, MPs have clear incentives to carefully work their profile and monitor its development. This is manifest in the 2006 case of U.S. congressional staff members editing their superiors' Wikipedia profiles. ${ }^{5}$ In addition, as of late there has been a rapid growth of Twitter bots tracking edits to Wikipedia articles originating in state institutions such as the U.S. Congress, German federal institutions, or the Danish Folketing, which reveals that such edits are not a rarity. ${ }^{6}$ Results from our analysis confirm existing evidence for MPs editing politicians' Wikipedia profiles. 
Given the attractiveness of the platform as a means of subtle political communication, what are our expectations about its use by MPs to polish their appearance? To begin with, considering that our theoretical argument marks the importance of the platform for electoral purposes, we generally expect the temporal context of election periods to matter. Accordingly, we anticipate editing activity to be increased before or during election campaigns, when constituents are expected to inform their voting choice and races tend to become more competitive.

Still, we would not expect every candidate to use the platform equally because benefits vary across MPs. In particular, we expect the electoral system to play an important role in that regard. In line with established theories of vote seeking (e.g., Carey \& Shugart, 1995; Fenno, 1978; Mayhew, 1974), we argue that especially representatives with a district base, seeking reelection, cultivate a personal vote and devote themselves to advertising (e.g., speeches, interviews, and online formats), credit claiming (e.g., pork), and position taking (e.g., votes). Personal vote-seeking behavior should occur mainly in systems where candidates run on a personal ticket (e.g., single-member plurality systems) and should be less prevalent in systems where people vote for parties not candidates (e.g., PR systems with closed party lists). The German case with its mixed electoral system provides an intriguing setting to study the influence of electoral incentives on MP behavior. In a nutshell, voters can cast two votes - one on a district candidate and one on a party list. About half of the seats in parliament are distributed to MPs directly elected in their constituency, whereas the other half goes to MPs who have succeeded on the party list. District candidates in Germany hence run more individualized campaigns (Zittel \& Gschwend, 2008) and, elected on that base, cater more to their personal geographic reelection constituency than their list counterparts focusing on party reelection (Stratmann \& Baur, 2002). This also seems to apply to various online forms of campaigning (Zittel, 2015). Following this evidence, we expect district MPs to be more active on their own Wikipedia entries than MPs elected on the list ticket. $^{7}$

We furthermore predict regional differences between MPs' electoral bases to account for some of the variation in editing activity. Even many years after the Iron Curtain was lifted, studies report a digital divide in Internet use between the Western and the Eastern, former German Democratic Republic (GDR) part of Germany (Korupp \& Szydlik, 2005). ${ }^{8}$ Lower Internet use in East Germany was shown to be driven by higher unemployment rates, lower incomes, lower professional qualifications, and less developed infrastructure than in Western Germany (Schleife, 2010), all factors that should be well known to politicians. We thus expect politicians elected in Western Germany to attach greater importance to their Wikipedia biographies than those in Eastern Germany.

Moreover, arguing from a partisan perspective, we assume party affiliation to play a role. We have, however, no clear expectation as to the direction of the effect an MP's party membership might bring about. Regarding the last couple of elections in Germany, the smaller parties targeted a younger audience which is probably more susceptible to online campaigning (Jung, Schroth, \& Wolf, 2010). At the same time, these parties hold fewer resources necessary to have their biographical entries traced and edited at their discretion than their bigger rivals and, perhaps more importantly, often lack the electoral incentives because candidates of the two major parties take most of the district seats.

Next, we hypothesize that younger candidates are more used to the Internet (see also Brown, 2011; Zittel, 2015) and therefore more likely to adopt an advertising strategy on Wikipedia. In a similar vein, we follow studies indicating that gender differences exist in online campaigning approaches (Druckman et al., 2007, p. 437) as well as in terms of Internet use (Korupp \& Szydlik, 2005; Schleife, 2010). As predictions are in part contrary, however, we again have no clear expectations as to the direction of a possible effect.

Finally, we would think that the popularity of a candidate matters for whether she decides to become an active editor on her Wikipedia biography. Manipulation of the personal entry in the encyclopedia might be more easily detected and make for a larger public outcry for these candidates, 
since they are in the center of public and media attention. We accordingly expect popular MPs to weigh the costs and benefits of editing differently than nonpopular MPs, yielding less editing activity. In sum, we investigate both individual- (party affiliation, gender, age, and popularity) and contextual-level (electoral system and cycle, regional digital disparities) incentives to edit biographical entries on Wikipedia.

\section{Data and Research Design}

While Wikipedia is used as an information source throughout the world, we opted for the German case for the following reasons. As elaborated earlier, Germany's mixed electoral system allows examining how different electoral incentives bear on MPs' behavior on Wikipedia. Compared to cross-country comparisons, this choice provides a somewhat more controlled setting, as otherwise heterogeneous contextual factors are held constant (Gschwend, 2007; Hirczy, 1994). The Germanlanguage edition of Wikipedia is also the fourth largest, housing the second largest number of edits. ${ }^{9}$ Furthermore, a Wikipedia entry exists for all MPs who have taken part in the legislative terms considered here. ${ }^{10}$ This warrants a certain popularity, making it more likely that MPs and party followers at the grassroots explore Wikipedia for campaigning purposes. Indeed, Germany scores second highest on Wikipedia's audience share (see Note 1) among other democracies with similar electoral systems, ${ }^{11}$ and the popularity of MPs' Wikipedia profiles is also evident in article traffic statistics, which we present in the next section. Findings from the German case further speak to the role of Wikipedia for politicians in a variety of other political systems. For instance, if constituencyelected MPs pay more attention to their Wikipedia profiles than list-elected MPs, we expect our findings to travel to other countries, in the sense that politicians in very individualized contexts like the United States or the United Kingdom, employing first-past-the-post voting, are more likely to pay attention to their Wikipedia profiles than politicians in party-centered systems such as Spain or Israel, employing closed party lists. Generalizations based on the German case thus help to identify settings in which future research on this topic can be conducted most fruitfully.

The data we use to analyze edit practices on German MPs' Wikipedia pages pertain to all 1,100 members of the Bundestag in the three preceding terms, making for 1,938 observations. ${ }^{12}$ It captures different dimensions and sources of edits, page metrics, and political as well as sociodemographic MP characteristics.

Edit data were collected from Wikipedia edit histories. These were accessed directly using web scraping techniques. ${ }^{13}$ Based on Wikipedia lists of Bundestag MPs that link to each MPs' individual Wikipedia page (see Note 9), the HTML file of each pages' edit history was collected in a first step. In a second step, we extracted information on edits from these HTMLs, using XPath and regular expressions. We then processed this information to obtain measures of the total number of edits as well as the overall count of insertions, deletions, and reverts made to each MPs' profile. For each of these measures, we additionally identified the portion stemming from the Bundestag. To do so, we considered only the edits featuring an IP address that is linked to the Bundestag IT network. ${ }^{14}$ This is possible because Wikipedia automatically publishes an author's IP address the moment she acts as an unregistered and thus anonymous user. We emphasize that our analyses are fully in line with data protection regulations, as all IP addresses we work with have been made publicly available with the consent of their respective owners.

One might object that our approach does not capture MPs' activity directly — as the IP does not inform about whether the edit was conducted by an MP, her staffer, or a political rival—or comprehensively - as MPs may well act as registered users. As to the former, we argue that it seems rather unlikely that more than a minority of edits on MPs' Wikipedia pages refers back to rival MPs, given the growing public and media attention and thus the risk involved in editing political rivals' profiles. In fact, we hardly find edits containing negative information about the portrayed MP in our 
qualitative research (see subsequently). This still leaves staffers to be potentially responsible for most of the edits. However, we argue that the same incentives should apply for both staffers and their MPs. We thus assume that edits related to Bundestag IPs are either stemming from the respective MPs or from staffers acting on their behalf. ${ }^{15}$ Accordingly, when referring to MPs throughout the article, this always includes staffers and other persons likely to act on MPs' behalf. Following this assumption and concerning the issue of comprehensiveness, the applied measure is potentially underreporting MPs' editing activities. Unfortunately, as the IP addresses of registered users are only accessible by few trusted Wikipedia users, it is impossible for us to assess the degree of this bias.

In addition to these numerical measures, it would be desirable to identify the quality of changes. However, the evidence we provide later on shows that it is very difficult to automatically classify the character of edits, that is, whether they are merely technical or substantive in nature, as they do rarely share common semantic features that could be picked up by natural language-processing or text mining techniques. Considering the massive number of observed edits, we also refrain from a human coding strategy. Instead, we manually surveyed a small fraction of edits from both popular and nonpopular MPs to arrive at a first rough typology of the motives behind editing efforts. Note, however, that this typology is not based on a full content analysis and thus not exhaustive. It merely serves to put some flesh on the bones of our theoretical argument.

Page metrics were included in our data to heed the role a page's popularity might play in the amount of editing to which it is subjected. We gathered aggregate page view data (Meißner and $\mathrm{R}$ Core team, 2016) and the change in a page's length in kilobytes (kBs) throughout each term for each MP's Wikipedia page.

Given that we are interested in the factors driving politicians' editing behavior, we accumulate our data set with political and sociodemographic MP characteristics taken from MPs' personal Wikipedia and Bundestag pages, using the abovementioned scraping approach. This includes gender, age, the geographical location of the district in which an MP was elected, party affiliation, and mandate type.

We analyze our data in three steps. First, we look at descriptive statistics and highlight some core features in our data. In doing so, we also detail the qualitative varieties of edits to illustrate the political motivation behind editing. Next, we investigate the flow of edits over time to test our theoretical expectations by linking edits to political events. To better understand the factors driving editing behavior, we conduct regression analyses. Our data are negatively skewed, and for many MPs, no edits to biographical entries from the parliament's IP range are recorded (see Figure 1b). We hence estimate zero-inflated negative binomial (ZINB) models for overdispersed count data with excessive zeros (King, 1988). Several test statistics support our choice over alternative models (see Supplementary Table A1).

ZINB models consist of two consecutive regressions: a logistic regression modeling the occurrence of zeros, that is, the probability that editing occurs or not, and, building on that, a negative binomial regression modeling the incidence rate. While we include all variables in the second part, we omit gender and party in the first. This is mainly because we have no clear expectations regarding the effects of these variables. In consequence, we lack any theoretical basis for claiming gender and party to determine whether politicians' Wikipedia entries exhibit edits from the parliament in the first place. Furthermore, the party predictor presents the highest correlation with other predictors (up to 0.48 ). This clustering of values within parties causes the party predictor to soak up some of the variation originally due to other variables. Alternative model specifications neither reveal meaningful patterns for the party predictor nor alter our central findings (see Supplementary Table A4).

We consider three additional models with varying sample sizes as robustness checks to our original specification. Heeding that only very few MPs show a large number of edits, we replicate our analysis with the sample cut to the 99.5th as well as the 99th percentile of edits to check for influential observations. As we observe differences in attention received by popular (more than 


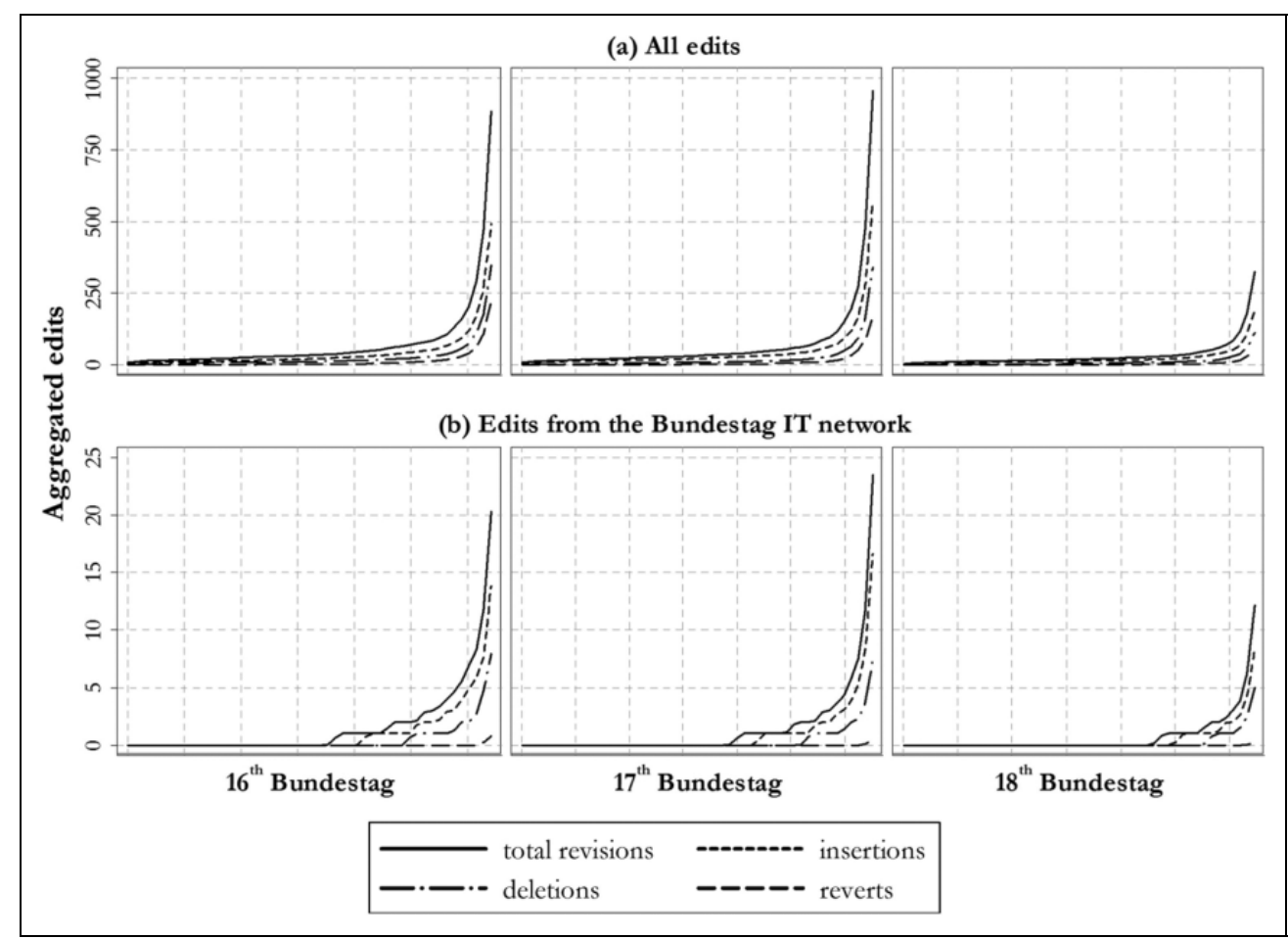

Figure I. Members of parliament (MPs) ordered by Wikipedia page edits. For (a) $N=44,558$ (I6th term); 43,355 (I7th term); 20,862 (I8th term). For (b) $N=1,017$ (I6th term); 90 I (I7th term); 447 (I8th term).

50 page views per day on average) and nonpopular MPs on Wikipedia (see Figure 2), we also run a model that excludes popular MPs. Using other cutoffs to identify popular MPs, for example, 25 or 100, did not substantively affect the estimates. All models are fitted with robust standard errors clustered by legislator. This is necessary, as most MPs are observed repeatedly across legislative terms. Observations related to one legislator's Wikipedia entry are thus likely to correlate with each other.

\section{Results}

German MPs' Wikipedia pages have been subject to 108,775 edits in the last three legislative sessions (see Note 12 for exact time spans). During these sessions, MP profiles did not receive equal amounts of attention, in terms of both editing activity and public interest. ${ }^{16}$ Aggregate daily page views of MPs' Wikipedia entries (50th percentile = 18,321 individual views; see Figure 2) document the importance of these biographies for the public to get informed and thus for MPs' individual campaigning efforts. Yet, while MP profiles received relatively constant attention, the intensity is highly dependent on particular political events, such as elections, and even more so on personal affairs and politicians' popularity. Accordingly, the largest peaks in attention occur at events linked to not more than 5 of the 1,100 MPs sampled here, minister resignations being the top sellers. This is in line with the skewed distribution of edits (see Figure 1a), indicating that only a fraction of MPs' Wikipedia entries is heavily edited and contested. In none of the three periods does the median number of edits exceed 33, while more than 100 edits cannot be found below the upper $13 \%$ (99th percentile $\geq 250$ ). Interestingly, reverts are rare events (75th percentile $\leq 7$ ), suggesting that edit wars revolving around MPs' Wikipedia entries are not an issue. The generally lower 


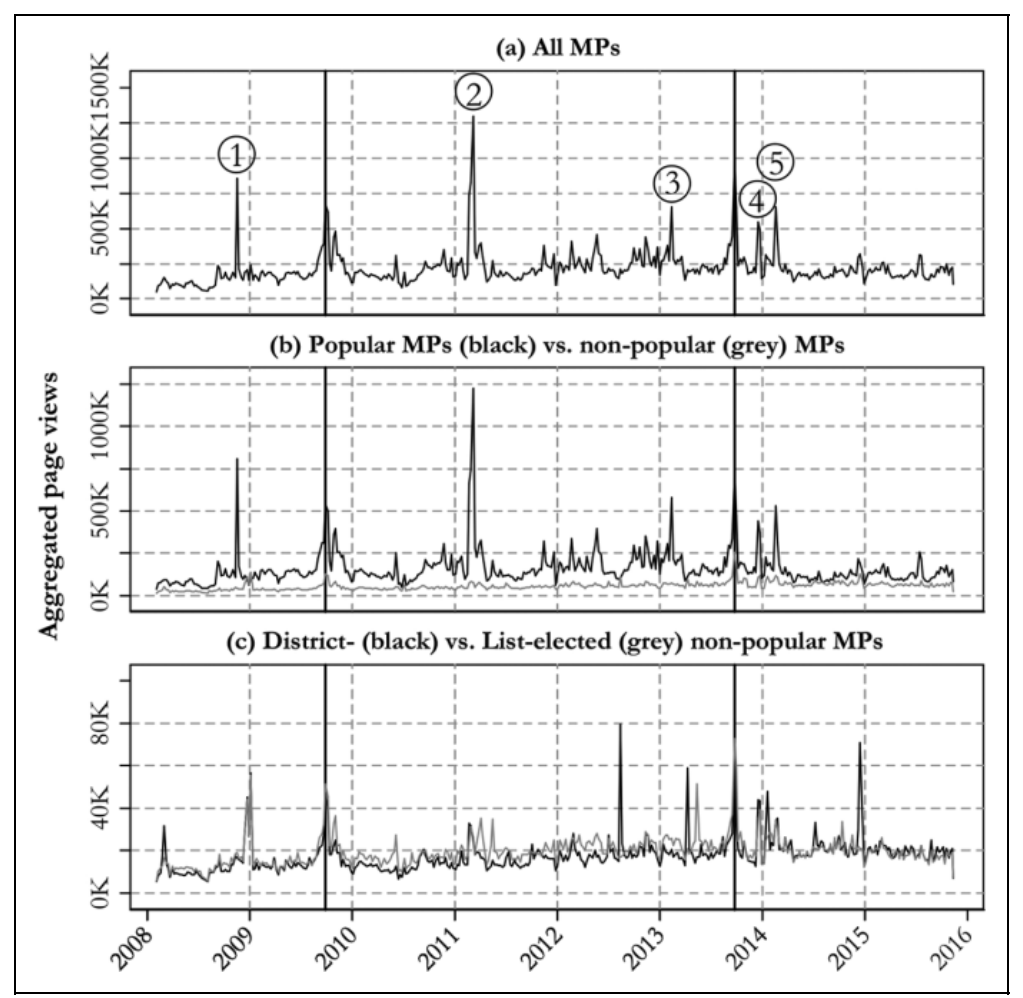

Figure 2. Page views of MPs' Wikipedia entries over time. MPs exhibiting on average more than 50 page views per day are categorized as popular. Circled numbers refer to events that arose significant interest: (1) Lutz Heilmann affair (see bottom Table 2); (2) demission of Karl-Theodor Freiherr von und zu Guttenberg, Minister of Defense; (3) demission of Anette Schavan, Minister of Education and Research; (4) appointment of new Merkel cabinet after 2013 election; and (5) demission of Hans-Peter Friedrich, Minister of Food and Agriculture. Solid vertical reference lines denote Bundestag elections. $M P=$ members of parliament.

number of edits for the 18th Bundestag should be seen in light of the data capturing only half of the term, as it is still ongoing.

Looking at edits originating from the Bundestag IT network, we find that $51 \%$ of the MPs represented in the last three legislative sessions had their Wikipedia page edited from an IP address linked to the parliament. Altogether, a full $2.2 \%$ of all edits can be traced back to MPs. Given the massive number of overall edits, this fraction amounts to more than 2,300 edits and can thus not be easily dismissed. Notwithstanding this aggregate picture, it is also apparent that a substantial number of MPs in each of the three sessions shows no edits coming from the parliament (see Figure $1 \mathrm{~b}$ ). ${ }^{17}$ Among those found to edit their profile, however, considerable variation exists. Edits range from a minimum of 1 to a maximum of 55, with higher frequencies being again reserved to a rather small portion of MPs (95th percentile $\leq 8$ ). Below, we strive to explain this variation. Like for all edits, MPs are more engaged in adding than in deleting content and reverts hardly exist. This suggests that MPs are more committed to enhance their web presence on Wikipedia and provide information instead of attempting to disappear in the shadows by removing undesired information.

This last statement, however, must be handled with caution. While the insertions-deletions dichotomy provides a first indication of where MPs are headed with their editing efforts, it does not inform about the very specific quality and rationale of editing behavior. Table 1 reports seven ways of editing we identified in a qualitative assessment of the data. Apart from nonsubstantial edits 
Table I. Typology of Edits From the Bundestag IT Network.

\begin{tabular}{|c|c|c|c|c|}
\hline & Category & MP and IP Address & Date & Content \\
\hline \multirow[t]{2}{*}{ I. } & Nonsubstantial edits & $\begin{array}{l}\text { Gesine Lötzsch } \\
\qquad(193.17 .243 .103)\end{array}$ & July 29, 2008 & Tense and party name corrected \\
\hline & & $\begin{array}{l}\text { Martin Burkert } \\
\quad(193.17 .243 .1)\end{array}$ & $\begin{array}{l}\text { September } \\
19,2013\end{array}$ & Typo corrected \\
\hline \multirow[t]{2}{*}{2.} & $\begin{array}{l}\text { Private information } \\
\text { sharing }\end{array}$ & $\begin{array}{l}\text { Peer Steinbrück } \\
\quad(193.17 .244 .2)\end{array}$ & $\begin{array}{l}\text { June } 17 \\
2013\end{array}$ & $\begin{array}{l}\text { Participation in community housing project } \\
\text { and him living there shared }\end{array}$ \\
\hline & & $\begin{array}{l}\text { Gerda Hasselfeldt } \\
\quad(193.17 .232 .2)\end{array}$ & $\begin{array}{l}\text { January } 8 \\
2008\end{array}$ & $\begin{array}{l}\text { Childhood on a farm with butchery and inn } \\
\text { shared }\end{array}$ \\
\hline \multirow[t]{2}{*}{3.} & CV shaping & $\begin{array}{l}\text { Ilse Aigner } \\
\quad(193.17 .243 .4)\end{array}$ & $\begin{array}{l}\text { October 30, } \\
2006\end{array}$ & $\begin{array}{l}\text { Information concerning life and political career } \\
\text { added }\end{array}$ \\
\hline & & $\begin{array}{l}\text { Frank Schäffler } \\
\qquad(193.17 .243 .1)\end{array}$ & $\begin{array}{l}\text { September 5, } \\
2006\end{array}$ & $\begin{array}{l}\text { Supplement "FH" removed from a degree } \\
\text { received at a University of Applied Sciences } \\
\text { (FH) }\end{array}$ \\
\hline \multirow[t]{2}{*}{4.} & Campaign information & $\begin{array}{r}\text { Kerstin Andreae } \\
(193.17 .232 .3)\end{array}$ & $\begin{array}{l}\text { July I5, } \\
2009\end{array}$ & $\begin{array}{l}\text { Weblinks to campaign and Facebook page } \\
\text { added }\end{array}$ \\
\hline & & $\begin{array}{l}\text { Michael Grosse- } \\
\text { Brömer } \\
(193.17 .243 .1)\end{array}$ & $\begin{array}{l}\text { August 20, } \\
2009\end{array}$ & Weblink to page for Bundestag election added \\
\hline \multirow[t]{2}{*}{5.} & $\begin{array}{l}\text { Highlighting of } \\
\text { successes }\end{array}$ & $\begin{array}{l}\text { Sebastian Edathy } \\
(193.17 .243 .1)\end{array}$ & $\begin{array}{l}\text { October 14, } \\
2009\end{array}$ & $\begin{array}{l}\text { Statement of him scoring very high in elections } \\
\text { compared to colleagues added }\end{array}$ \\
\hline & & $\begin{array}{l}\text { Michael Stübgen } \\
\quad(193.17 .244 .3)\end{array}$ & $\begin{array}{l}\text { September } \\
19,2013\end{array}$ & $\begin{array}{l}\text { Information of reelection as CDU district } \\
\text { association chairman with over } 90 \% \text { of the } \\
\text { votes added }\end{array}$ \\
\hline \multirow[t]{2}{*}{6.} & Positive reframing & $\begin{array}{l}\text { Jens Ackermann } \\
\qquad(193.17 .243 .1)\end{array}$ & $\begin{array}{l}\text { January } 28 \\
2010\end{array}$ & $\begin{array}{l}\text { "Failed" changed to "achieved," } \\
\text { "nevertheless" removed from "entered the } \\
\text { Bundestag nevertheless" }\end{array}$ \\
\hline & & $\begin{array}{l}\text { Anette Hübinger } \\
(193.17 .232 .2)\end{array}$ & $\begin{array}{l}\text { February } 3 \text {, } \\
2014\end{array}$ & $\begin{array}{l}\text { Just having managed to defend the district } \\
\text { mandate in a tight race replaced by having } \\
\text { "once again managed to defend the } \\
\text { mandate" }\end{array}$ \\
\hline \multirow[t]{2}{*}{7.} & $\begin{array}{l}\text { Removal of possibly } \\
\text { harmful information }\end{array}$ & $\begin{array}{l}\text { Thomas } \\
\text { Oppermann } \\
(193.17 .244 .1)\end{array}$ & May 8, 2013 & $\begin{array}{l}\text { Membership in control commission of state } \\
\text { association "Sozialistische Jugend } \\
\text { Deutschlands" }\end{array}$ \\
\hline & & $\begin{array}{l}\text { Lutz Heilmann } \\
\qquad(193.17 .232 .2)\end{array}$ & $\begin{array}{l}\text { November 6, } \\
2008\end{array}$ & $\begin{array}{l}\text { Weak intraparty support and "Stasi" record } \\
\text { removed }\end{array}$ \\
\hline
\end{tabular}

Note. Bold dates denote edits occurring in close vicinity to election dates.

that address spelling mistakes, grammar errors, or typos, they all expose strategic motivations of political advertising. For example, MPs are found to supplement their biographical entry with private information in ways that seem geared to generate sympathies by bringing them closer to their respective constituents. In the case of Gerda Hasselfeldt for instance, chairperson of the Christian Social Union (CSU) parliamentary group, the information that she spent her childhood on a farm with butchery and inn was added to the very beginning of her Wikipedia profile. This could indicate an attempt to adapt to her rural electorate in her Upper Bavarian' electoral district. In advance of federal elections, MPs also turn to their Wikipedia entry to provide for campaignrelated information. In the case of Kerstin Andreae, deputy chairperson of Bündnis 90/Die Grünen, web links to her personal campaign and Facebook page were placed on her entry. Another type of editing we observe is the removal of possibly adverse information, such as in the case of SPD Chairman Thomas Oppermann, whose membership in the control commission of the leftist 


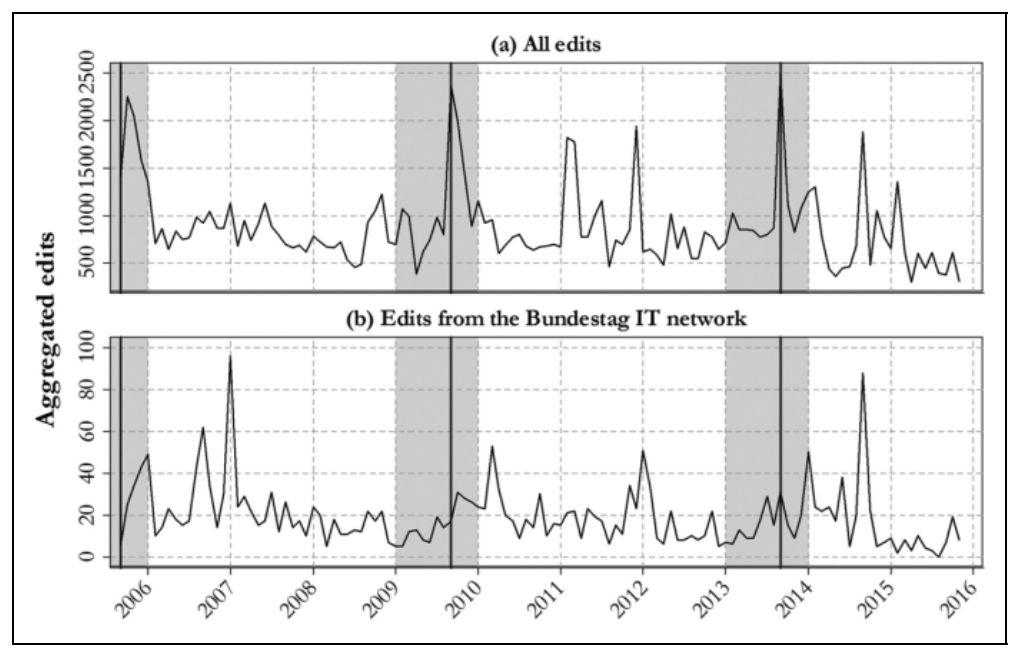

Figure 3. Edits on members of parliament (MPs') Wikipedia entries over time. For (a) $N=108,775$; for (b) $N=$ 2,365. Edits only cover MPs with a seat in the Bundestag during the respective period. Reference lines denote Bundestag elections, shaded areas the election years.

North Rhine-Westphalia state association "Sozialistische Jugend Deutschlands_-Die Falken" was deleted from his page, while his membership in the conservative party group "Seeheimer Kreis" was left untouched. This might reflect an attempt to appeal to his more conservative voters. These examples provide substantive support for our initial expectation that MPs' use their Wikipedia profiles for political advertising.

\section{Temporal Editing Trends}

Figure 3a demonstrates how edits made to German MPs' Wikipedia pages are distributed over time. In accordance with the public attention reported in Figure 2, MP biographies are constantly subject to editing efforts that are heavily concentrated around federal elections. Discriminating between popular and nonpopular MPs (see Figure $2 b$ and $c$ ) leaves attention to the majority of MP pages (nonpopular) primarily peak around elections. Other peaks in editing are thus likely to be due to political events linked to popular MPs.

With respect to edits originating from the Bundestag IT network, the picture is less clear-cut. As shown in Figure 3b, peaks are neither as intense nor as frequent as in Figure $3 \mathrm{a}$ and do not occur during election periods. Instead, editing appears to be relatively constant throughout election cycles pointing to the political importance the platform unfolds in day-to-day politics. This suggests that MPs view their biographical entries on the platform and possible effects on voters as too important to leave them unchecked until shortly before Election Day.

What is interesting is that edit rates seem to increase throughout the year when focusing on election years. Note, however, that edits at the time of elections can be due to different causes, reflecting electorally motivated efforts and mere updates of information alike. Figure 4 thus provides a more detailed snapshot of the editing activity during election years and months that helps us discern between these motifs. Importantly, all three electoral periods under investigation exhibit constant pre- and postelectoral editing efforts by MPs. In addition, the highest peaks in 2009 and 2013 show up at elections. Especially, in the run-up to the 2013 federal election, edits appear primarily during the election week and across the election month. This indicates that MPs polish their Wikipedia appearance for upcoming elections. The clustering of edits in the aftermath of all three elections is notable, 


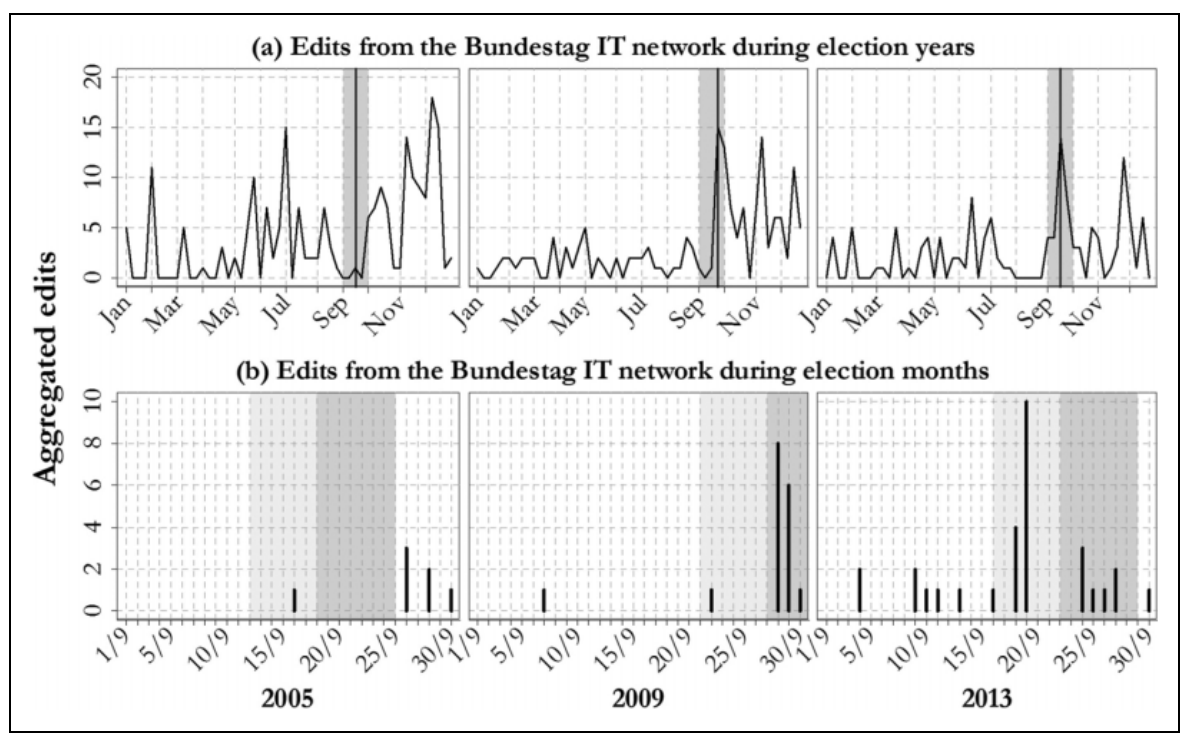

Figure 4. Edits on members of parliament (MPs') Wikipedia entries from the Bundestag IT network during elections. For (a) $N=187$ for 2005; I 55 for 2009; and I 29 for 20 I3. Reference lines denote election weeks. For (b) $N=6$ for 2005; 17 for 2009; and 30 for 2013. The lighter shade depicts the preelection week, the darker shade the postelection week. For each year, edits cover only MPs with a seat in the preelectoral term.

too. Newly and reelected MPs may feel the need to monitor and control their biographies more strongly while they are more likely to become subject to public and media attention.

\section{Political and Sociodemographic Factors of Editing Behavior}

As concerns the rationale behind editing efforts on politicians Wikipedia pages, we assume that incentives for editing are not the same among MPs. This is already apparent from the substantial amount of MP biographies not featuring any edits from the Bundestag network. Accordingly, we consider it important to first explore the conditional probability that MPs' profiles do not exhibit edits from the parliament's IP range (see Table 2 and Figure 5, left part) as given by the logit regression in the ZINB models. As expected, list MPs are less likely to edit their own profile (8-10\%). This highlights reelection motifs, which are stronger for district-based MPs, as we argue. In line with our regional digital divide argument, MPs from East German states are considerably less likely to edit their profiles than those elected in West German states (17-23\%). MPs running in East Germany might indeed feel less of an electoral need to actively develop their online appearance. Corroborating previous findings, there tend to be differences between younger and older MPs as regards general editing probability (7-9\% per SD). Technological and media competence thus seem to play a role in whether MPs edit their biographies or not. Interestingly, MPs are found to be less likely to work their profile as page views rise (4-9\% per $S D$ ). This corroborates our hypothesis that popular MPs assess the costs and benefits of editing differently. In addition, we find that the amount to which MP biographies grow in length between legislative sessions plays a role in that the more extensive they get, the more likely MPs are to engage in editing ( $1 \%$ per $S D$ ). This makes substantive sense and indicates that MPs deem it necessary to become active and monitor their profiles more closely if they hold more information about them. With the critical election phase not yet reached for the 18th legislature, it is not surprising that MPs from this period are more likely not to edit their page. 


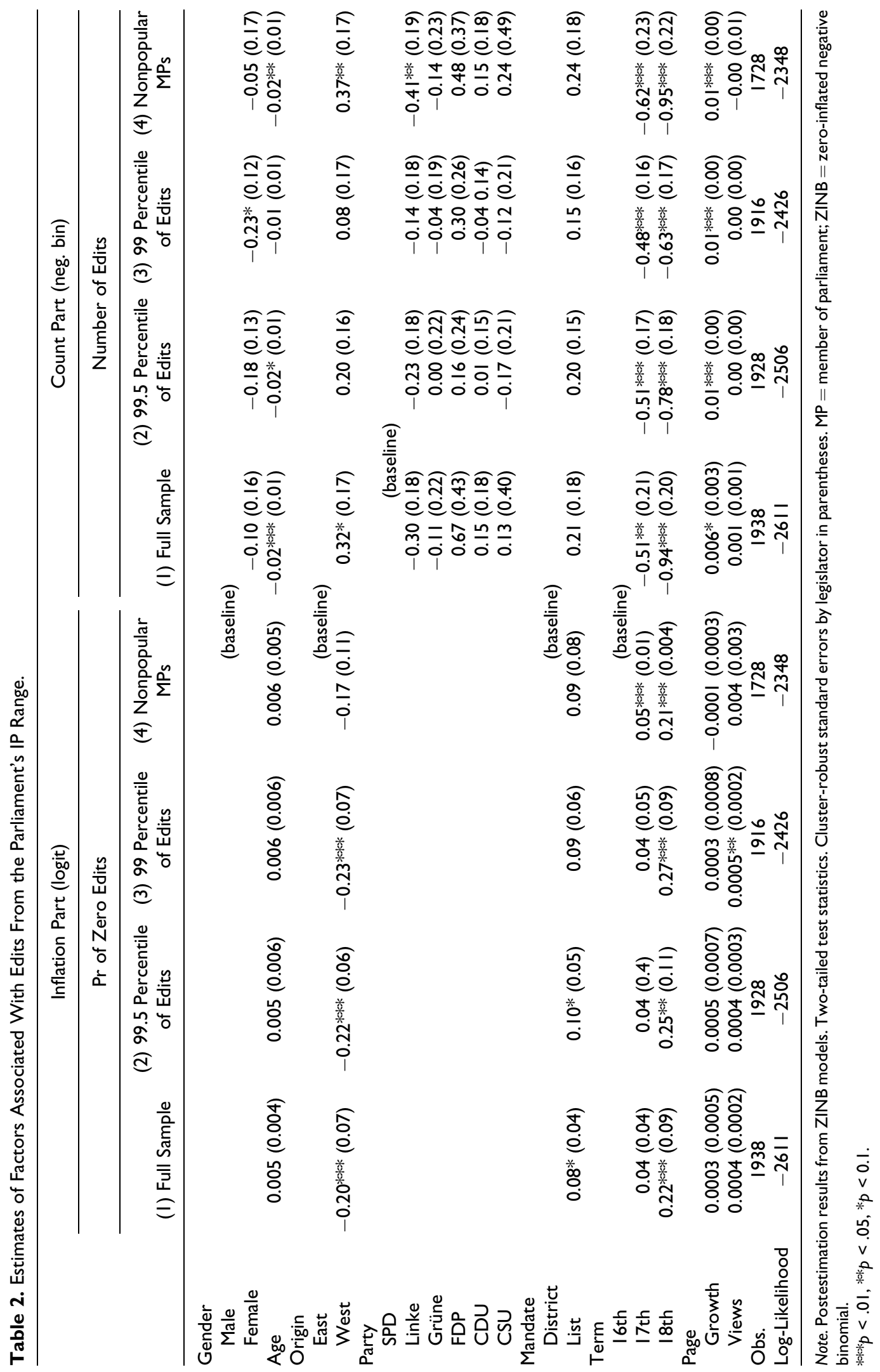




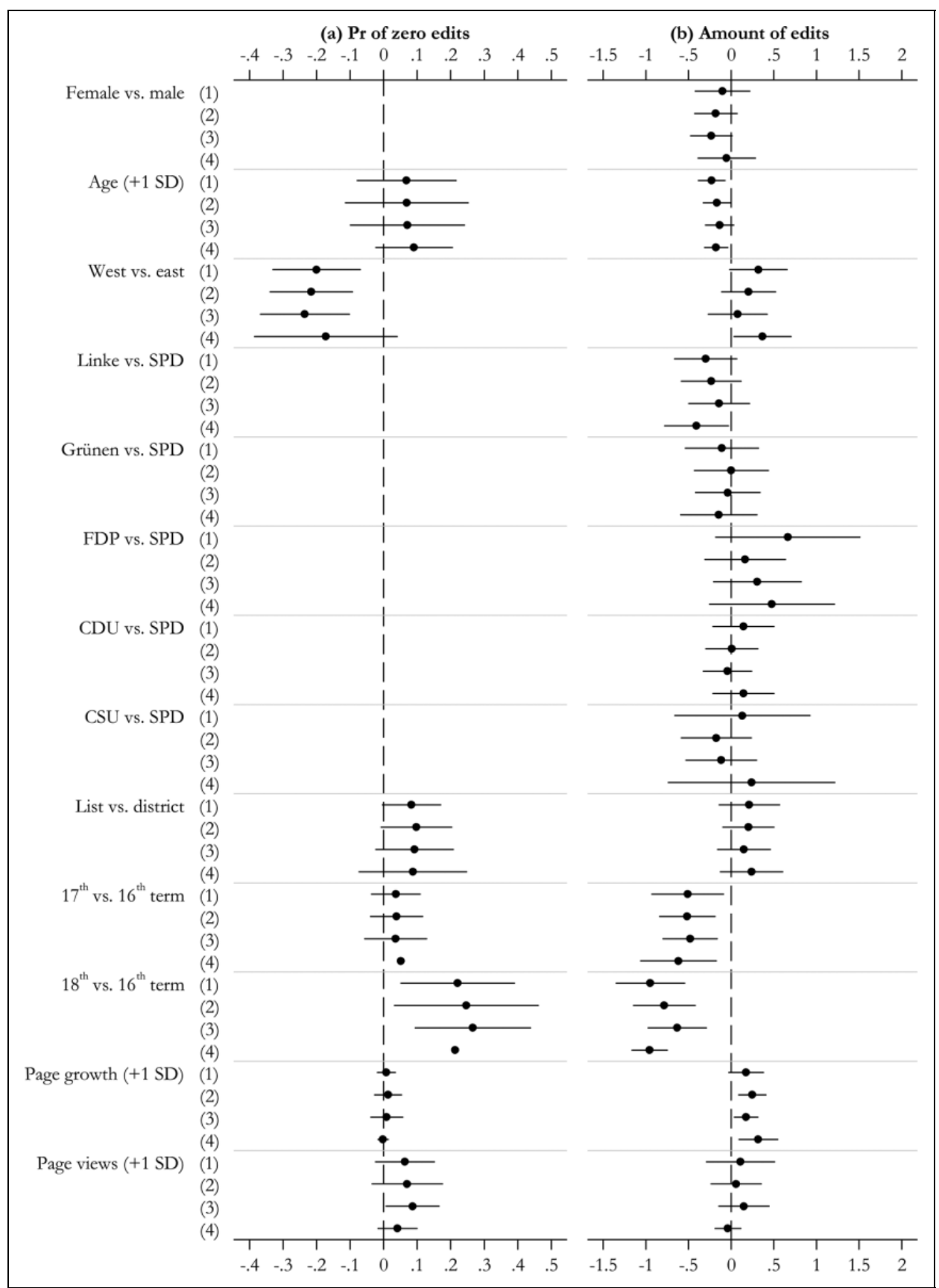

Figure 5. First differences in factors associated with edits from the parliament's IP range. Based on zeroinflated negative binomial models in Table 2. Computed holding each of the other predictors not at their means but at the observed values for each case in the sample. Solid lines denote $95 \%$ confidence intervals.

Finally, we look at the number of edits for those MP profiles actually edited from within the parliament (see Table 2 and Figure 5, right part). First of all, list MPs tend to exhibit more edits than district MPs (0.2 edits; $14-20 \%)$. This pattern suggests that personal vote incentives matter only for 
the decision to edit but not for the frequency of editing. The above-found divide between elected East and West German MPs is again apparent (0.1-0.4 edits; 7-37\%), lending additional support to the regional digital divide argument. As for party differences, editing tends to increase slightly toward the center of the political spectrum, but this pattern is not very robust across model specifications. Ultimately, this confirms that politicians' activities on Wikipedia cut through party divisions and highlights the platform's value for party-independent actions. Similarly, it shows that resource constraints, varying between parties, do not play a great role on Wikipedia. The generation gap is observable for the frequency of edits, too (0.1-0.2 edits; $1-2 \%$ per $S D)$. Technological gender divisions seem to be present $(0.1-0.2$ edits, $4-18 \%)$, and the role of MP popularity vanishes for the intensity of editing activity. The latter indicates that MPs do not restrict themselves on that ground anymore once they have decided that the benefits of editing outweigh the costs. Finally, we find MPs whose pages show larger growth rates to edit their profiles more actively $(0.2$ edits; $1 \%$ per $S D)$. This effect is not self-evident, as the portion of edits from the Bundestag network is by far not large enough to increase page growth to the point that it causes this correlation by itself. It rather shows that MPs do not build their profiles from scratch but become more active editors if other users provide more information. This in turn suggests that MPs are primarily engaged with monitoring, reframing, or adjusting existing content which makes sense given politicians limited resources.

\section{Discussion}

Is Wikipedia joining the ranks of social networking services as political communication devices and tools for electoral campaigning? Research summarized in this article indicates that Wikipedia fulfills this function for users and MPs alike. Our results show that MP biographies on Wikipedia represent a frequently used source of information for the public. German MPs and their staff seem to have realized this. The factors identified to drive editing behavior indicate that MPs have internalized the possibilities offered by the platform in a political and strategic manner. Accordingly, whether and to what extent MPs use Wikipedia for advertising and communication purposes seems to hinge on the expected benefits determined by contextual factors such as requirements to cultivate a personal vote, the Internet's general importance in the electoral base, and the scope of the own Wikipedia entry. Individual factors such as reputation costs and MPs age - widely equated with technological abilities and taken as important determinant of adaption to digital opportunities - also play a role in whether and how frequently MPs work their Wikipedia entry. While our approach cannot rule out alternative explanations for editing, such as vanity, the identified behavioral patterns coincide with how rational politicians are generally expected to act. This also makes us more confident that the edits we trace indeed emerge from the hands of politicians. The finding that the provision of content spearheads MP editing further corroborates that MPs are actively embracing and using the additional opportunities granted by Wikipedia's structural features. The ways in which MPs do so are manifold, including the strategic placement, modeling, removal, highlighting, or reframing of information. Importantly, the above holds both during election phases, confirming strategic motifs, and in day-to-day politics, showing that Wikipedia is not merely a fair-weather friend but a constant companion for users and MPs.

But why bother? The empirical patterns presented here offer two answers to this question: First, Wikipedia indeed proves to be not only a popular but actually widely used outlet for both the consumption (see Figure 2) and the distribution and negotiation (Figure 3) of biographical and political information about legislators. This gives politicians' Wikipedia biographies the capability to assist a substantial number of citizens in forming their political preferences. We therefore think that it is well worth knowing where this information originates from, who takes part in its production, and for what purposes. Second, at least in Germany, legislators seem to actively participate in the production and negotiation of this particular kind of information (see Figures 3 and 4). This matters because the fact that the platform allows politicians to stay cloaked while doing so provides 
for new and unmatched means to "invisibly" interfere in citizens' preference formation. The active use of these means is likely to affect if and how citizens cast their vote, think of politicians or politics in general, seek further information, and practice many more politically related activities.

This said, the results reported here have joint implications for studies investigating the determinants of voting behavior and the professionalization of politics. Recent research demonstrated that candidate valence, the characteristic traits of a candidate, elicits considerable effects on vote choice reaching beyond ideological proximity and issue-specific predispositions (Nyhuis, 2016). With this in mind, the sandpapering of online biographies by politicians on trusted platforms seems likely to elicit electoral effects. This in turn speaks directly to research addressing the ongoing professionalization of politics which increasingly results in the chief aim to distract and manipulate voters to fall in line with politicians' personal political agendas (Druckman \& Jacobs, 2015). So far, the literature has primarily shown how politicians advance this goal with traditional and rather direct methods of communication. Our research advances the menu of public opinion manipulation by providing evidence for politicians not shying away from using hidden, indirect ways to achieve their goals.

Our findings hold further implications for the general study of behavioral patterns using Wikipedia. For one, edits represent a behavioral measure that is not prone to various forms of bias associated with, for example, reports in candidate surveys (e.g., Bernauer \& Munzert, 2014; Zittel, 2015). In addition, nonresponse or other selection mechanisms are potentially less worrisome for the construction of our database, since we are able to identify Wikipedia articles for the entire population of MPs in the period we study. Other benefits are that activity can be measured at the daily level, which helps provide a fine-grained picture of action and reaction, and that additional metadata - such as the access volume of articles as an indicator of public attention-can be linked to behavior. Methodologically, a major caveat is that the question who edits on the platform cannot be answered with certainty - a problem that, however, also applies to reported answers in candidate surveys. Still, we believe that this new data source provides a unique opportunity to infer strategic behavior of political elites and that it presents, beyond methodological appeal, a substantively relevant object of study.

Finally, the findings produced by this article lay new tracks for future research. Are ordinary users and MPs plainly adding neutral information or are they rather pushing their political point of view or reframing content to their advantage? Here, one may follow the approach introduced by Lieberman and Lin (2009) and use information provided on user pages or users' editing focus as regards other Wikipedia content to identify outright party fighters. Following Kalla and Aronow (2015), it would further be revealing to learn how long edits stemming from the Bundestag IT network survived on Wikipedia. The life span of information suggests how broad a range of users was potentially exposed to and thus influenced by the respective information. The pressing question whether MPs' editing efforts on Wikipedia actually affect their electoral prospects may be investigated using experiments on crowdsourcing platforms. Here, experimental groups can be confronted with excerpts of political candidates' Wikipedia entries at different editing states in order to infer how editing influences participants' judgments about those candidates. Altogether, there remains much to investigate on Wikipedia.

\section{Authors' Note}

A previous version of this article was presented at a research workshop at MZES in May 2016 and at the 2016 EPSA General Conference, Brussels. We are grateful to Simon Hug, Richard Johnston, Andreas Jungherr, Thomas Meyer, and participants of the Media and Politics panel at the EPSA conference for very helpful comments on previous versions of this article, and Hannah Laumann for proofreading.

\section{Declaration of Conflicting Interests}

The authors declared no potential conflicts of interest with respect to the research, authorship, and/or publication of this article. 


\section{Funding}

The authors received no financial support for the research, authorship, and/or publication of this article.

\section{Supplemental Material}

Supplementary material for this article is available online.

\section{Notes}

1. As of January 2017, see http://www.alexa.com/siteinfo/wikipedia.org (retrieved January 9, 2017).

2. See https://de.wikipedia.org/w/index.php?title=Angela_Merkel\&diff=161785109\&oldid=161753466 for an example where Angela Merkel's Wikipedia entry is complemented with information about her asylum policy, an insertion. See https://de.wikipedia.org/w/index.php?title=Angela_Merkel\&diff= $161078087 \&$ oldid $=161018603$ for an example where supposedly duplicate information is removed from the same entry, a deletion. See https://de.wikipedia.org/w/index.php?title=Angela_Merkel\& diff $=161785146 \&$ oldid $=161785133$ for an example in which the abovementioned insertion is fully undone, a revert.

3. See https://en.wikipedia.org/wiki/Wikipedia:Neutral_point_of_view (retrieved January 9, 2017).

4. See https://meta.wikimedia.org/wiki/Research:Wikipedia_Readership_Survey_2011/Results (retrieved Jan 9, 2017).

5. See https://en.wikipedia.org/wiki/U.S._Congressional_staff_edits_to_Wikipedia (retrieved January 9, 2017).

6. See https://twitter.com/congressedits, https://twitter.com/bundesedit, and https://twitter.com/FTinget WikiEdit (retrieved January 9, 2017).

7. The mode of election is a proxy for electoral incentives that might be subject to contamination (e.g., Ferrara, Herron, \& Nishikawa, 2005). For instance, list elected members of parliament (MPs) may sometimes have incentives to appeal to voters in the district to mobilize party votes and thus increase their chance of being reelected. However, such contamination should, if anything, blur effects pertaining to the mode of election rather than pronounce them, which is why we consider our estimates conservative.

8. See the Online Atlas at http://initiatived21.de/app/uploads/2017/02/nonliner-atlas2005.pdf and http:// initiatived21.de/app/uploads/2017/01/studie-d21-digital-index-2016.pdf for the persistent disparities in Internet use and access between East and West Germany.

9. See https://en.wikipedia.org/wiki/German_Wikipedia (retrieved January 9, 2017).

10. The Wikipedia lists containing links to each MPs personal Wikipedia page can be accessed via https://de. wikipedia.org/wiki/Liste_der_Listen_der_Mitglieder_des_Deutschen_Bundestages (retrieved January 9, 2017).

11. Only Japan, having a very similar electoral system, scores higher. However, the Japanese Wikipedia is much less developed, and biographies are only available for a subset of MPs.

12. See the Online Supplementary Materials for a variable overview (see Supplementary Table A2) and summary statistics (see Supplementary Table A3). Many MPs were members of more than one legislative period, thus the larger amount of observations. Our data cover edits that occurred during the following periods: 16th Bundestag - September 18, 2005 (Election Day) to September 27, 2009 (Election Day); 17th Bundestag-September 28, 2009 (day after the election) to September 22, 2013 (Election Day); 18th Bundestag-September 23, 2013 (day after the election) to November 16, 2015 (data collection closed).

13. For an elaborate account of the specific methods we used, see Munzert, Rubba, Meißner, and Nyhuis (2015). For replication code, see the Online Supplementary Materials.

14. The IP address range of the Bundestag IT network lies between 193.17.232.0 and 193.17.247.255. See http://www.utrace.de/whois/193.17.232.0 (retrieved January 9, 2016).

15. Also note that empirical research on political campaigning that uses candidate surveys, press releases, or similar data rests on similar assumptions, as they are generated in a private setting. We cannot be sure whether the candidate herself or members of her staff produce the data that are exploited scientifically. It is generally assumed that assumptions about strategic behavior are nevertheless valid. 
16. See the Online Supplementary Materials for a comparison of page view and edit frequencies of a subset of MPs' Wikipedia pages to other Wikipedia entries (Supplementary Table A5 and A6).

17. On a methodological note, we regard our figure of MPs being active on Wikipedia as a rather conservative estimate, since we were only able to attribute edits from within the Bundestag IP network to MPs activity.

\section{References}

Bernauer, J., \& Munzert, S. (2014). Loyal to the game? Strategic policy representation in mixed electoral systems. Representation, 50, 83-97.

Brown, A. R. (2011). Wikipedia as a data source for political scientists: Accuracy and completeness of coverage. Political Science and Politics, 44, 339-343.

Brundidge, J., \& Rice, R. E. (2009). Political engagement online: Do the information rich get richer and the like-minded more similar? In A. Chadwick \& P. N. Howard (Eds.), Routledge handbook of internet politics (pp. 144-156). Abingdon, England: Routledge.

Carey, J. M., \& Shugart, M. S. (1995). Incentives to cultivate a personal vote: A rank ordering of electoral formulas. Electoral Studies, 14, 417-439.

Chong, D., \& Druckman, J. N. (2007). Framing theory. Annual Review of Political Science, 10, 103-126.

Dahlgren, P. (2005). The Internet, public spheres, and political communication. Political Communication, 22, $147-162$.

Das, S., Lavoie, A., \& Magdon-Ismail, M. (2011). Pushing your point of view: Behavioral measures of manipulation in Wikipedia. Computing Research Repository, 19. Available at: http://dblp2.uni-trier.de/ $\mathrm{rec} / \mathrm{bib} /$ journals/corr/abs-1111-2092

Druckman, J. N., \& Jacobs, L. R. (2015). Who governs? Presidents, public opinion, and manipulation. Chicago, IL: University of Chicago Press.

Druckman, J. N., Kifer, M. J., \& Parkin, M. (2007). The technological development of congressional candidate web sites. How and why candidates use web innovations. Social Science Computer Review, 25, 425-442.

Druckman, J. N., Kifer, M. J., \& Parkin, M. (2009). Campaign communications in U.S. Congressional elections. American Political Science Review, 103, 343-366.

Druckman, J. N., \& Parkin, M. (2005). The impact of media bias. How editorial slant affects voters. Journal of Politics, 67, 1030-1049.

Fenno, R. F. (1978). Home style: House members in their districts. Boston, MA: Little, Brown.

Ferrara, F., Herron, E. S., \& Nishikawa, M. (2005). Mixed electoral systems. Contamination and its consequences. New York, NY: Palgrave Macmillan.

Gibson, R. K., \& McAllister, I. (2011). Do online election campaigns win votes? The 2007 Australian "YouTube" election. Political Communication, 28, 227-244.

Giles, J. (2005). Internet encyclopaedias go head to head. Nature, 438, 900-901.

Gschwend, T. (2007). Ticket-splitting and strategic voting under mixed electoral rules. Evidence from Germany. European Journal of Political Research, 46, 1-23.

Hirczy, W. (1994). The impact of mandatory voting laws on turnout. A quasi-experimental approach. Electoral Studies, 43, 72-84.

Jung, M., Schroth, Y., \& Wolf, A. (2010). Wählerverhalten und Wahlergebnis: Regierungswechsel ohne Wechselstimmung. In K.-R. Korte (Ed.), Die Bundestagswahl 2009: Analysen der Wahl-, Parteien-, Kommunikations- und Regierungsforschung (pp. 35-47). Wiesbaden, Germany: VS Verlag.

Kalla, J. L., \& Aronow, P. M. (2015). Editorial bias in crowd-sourced political information. PLoS One, 10, e0136327.

King, G. (1988). Statistical models for political science event counts: Bias in conventional procedures and evidence for the exponential poisson regression model. Americal Journal of Political Science, 32, 838-863.

Korupp, S. E., \& Szydlik, M. (2005). Causes and trends of the digital divide. European Sociological Review, 21, 409-422. 
Lassen, D. S., \& Brown, A. R. (2011). Twitter: The electoral connection. Social Science Computer Review, 29, 419-436.

Lieberman, M. D., \& Lin, J. (2009). You are where you edit: Locating Wikipedia contributors through edit histories. Paper presented at the third International AAAI Conference on Weblogs and Social Media (ICWSM'09), San Jose, CA.

Mayhew, D. (1974). Congress: The electoral connection. New Haven, CT: Yale University Press.

Peter, Meißner, \& R Core Team (2016). wikipediatrend: Public Subject Attention via Wikipedia Page View Statistics. R package version 1.1.10. from https://CRAN.R-project.org/package=wikipediatrend

Mesgari, M., Okoli, C., Mehdi, M., Nielsen, F. A., \& Lanamäki, A. (2015). 'The sum of all human knowledge': A systematic review of scholarly research on the content of Wikipedia. Journal of the Association for Information Science and Technology, 66, 219-245.

Miller, J. M., \& Krosnick, J. A. (2000). News media impact on the ingredients of presidential evaluations: Politically knowledgeable citizens are guided by a trusted source. American Journal of Political Science, 44, 301-315.

Munzert, S., Rubba, C., Meißner, P., \& Nyhuis, D. (2015). Automated data collection with R: A practical guide to web scraping and text mining. Chichester, England: John Wiley.

Neff, J. J., Laniado, D., Kappler, K. E., Volkovich, Y., Aragón, P., \& Kaltenbrunner, A. (2013). Jointly they edit: Examining the impact of community identification on political interaction in Wikipedia. PLoS One, 8, e60584.

Nyhuis, D. (2016). Electoral effects of candidate valence. Electoral Studies, 42, 33-41.

Riehle, D. (2006, August 21-23). How and why Wikipedia works: An interview with Angela Beesley, Elisabeth Bauer, and Kizu Naoko. Paper presented at WikiSym'06, Odense, Denmark.

Schleife, K. (2010). What really matters. Regional versus individual determinants of the digital divide in Germany. Research Policy, 39, 173-185.

Schroeder, R., \& Taylor, L. (2015). Big data and Wikipedia research: Social science knowledge across disciplinary divides. Information, Communication and Society, 18, 1039-1056.

Stratmann, T., \& Baur, M. (2002). Plurality rule, proportional representation, and the German Bundestag. How incentives to pork-barrel differ across electoral systems. American Journal of Political Science, 46, 506-514.

Sumi, R., Yasseri, T., Rung, A., \& Kertész, J. (2012). Dynamics of conflicts in Wikipedia. PLoS One, 7 , e38869.

Utz, S. (2009). The (potential) benefits of campaigning via social network sites. Journal of Computer-Mediated Communication, 14, 221-243.

Zittel, T. (2015). Do candidates seek personal votes on the Internet? Constituency candidates in the 2009 German federal election. German Politics, 24, 435-450.

Zittel, T., \& Gschwend, T. (2008). Individualised constituency campaigns in mixed-member electoral systems: Candidates in the 2005 German elections. West European Politics, 31, 978-1003.

\section{Author Biographies}

Sascha Göbel is an MA student at the Department of Politics and Public Administration at the University of Konstanz. His research interests cover the study of (online) political behavior and communication, the political geography of elections and electoral institutions, and techniques for spatial visualization and text as data. Email: sascha.goebel@uni-konstanz.de

Simon Munzert is a postdoctoral researcher at the Department of Social Sciences at the Humboldt University of Berlin. His research interests include methods of election forecasting, public opinion measurement, and techniques for web scraping and Big Data management. Email: simon.munzert@hu-berlin.de 